\title{
Pattern of cancer in Sohag Governorate
}

\author{
Fouad M .Tasneem MohammedBakheet \\ Department of public health and community medicine, Faculty of medicine, Sohag \\ University, sohag, egypt \\ Public health and community medicine, Faculty of medicine, Sohag University
}

\begin{abstract}
Background: Cancer cases are increasing with time evolution in Egypt. There are an increasing number of the attendant cancer patients and the Outpatient Clinic affiliated to the Oncology and Nuclear Medicine department, Sohag University Hospital and Sohag Cancer Centre are facing difficulties with work pressure. As a consequence, the most prevailing types of cancer among patients suffering this entity of diseases must be addressed to ensure continual and improved quality of care Purpose: find out the pattern of cancer among cancer patients in Sohag governorate Methods: The researcher collected data from 550 patients. Clinical observational study "evaluative type" was conducted at Sohag University hospital (SUH), oncology and nuclear medicine department and Sohag Cancer Center (SCC) in Sohag governorate. Descriptive statistical techniques ,percentages and proportions were used Findings: Commonest sites of cancer in Sohag Governorate were cancer breast (29.9\%), then came lymphomas(9.7) and cancer bladder about (9\%) followed by colorectal cancer (8.2).

Conclusion: pattern of cancer indicated the increased burden of Breast cancer, comes after are lymphomas which occupy the second rank. Study of rates of individual sites of cancer might help in giving clues for preventive programs. Implementing value : essential for planning cancer control actions, health care and allocation of resources. Here we project the cancer burden at the National level estimate
\end{abstract}

Keywords

Cancer, prevalent types, Sohag, cancer burden.

\section{Introduction}

Cancer cases are increasing with time evolution in Egypt. There are an increasing number of the attendant cancer patients and the Outpatient Clinic affiliated to the Oncology and Nuclear Medicine department, Sohag University Hospital and Sohag Cancer Centre are facing difficulties with work pressure. As a consequence, the most prevailing types of cancer among patients suffering this entity of diseases must be addressed to ensure continual and improved quality of care.Oncologic specialty societies and multidisciplinary collaborative groups have dedicated considerable effort to assess the size of cancer

problem to facilitate the provision of quality health care and continuous improvement of thee needed comprehensive care, accreditation, benchmarking, reimburse-ent, maintenance of certificate-ion, and regulatory reporting. In particular, oncology as a field has a long history of organized quality assessment efforts and continues to work toward developing consensus quality standards in the face of continually evolving 
SOHAG MEDICAL JOURNAL

Vol. 24 No.1 Jan 2020
Pattern of cancer in Sohag Governorate

Tasneem Mohammed Bakheet technologies and standards of care (Albert,

2013).

\section{Subjects and method}

Clinical observational study "evaluative type" was conducted at Sohag University Hospital (SUH), oncology and nuclear medicine department and Sohag Cancer Center (SCC) in Sohag governorate. A representative sample of 550 patients from both hospitals participated in the questionnaire survey; $215(39.1 \%)$ from SUH and $335(60.9 \%)$ were from SCC. The required data were collected using a well-structured questionnaire consisting of two parts. The first part of the questionnaire included items to determine the studied patients' demographic characteristics such as age, sex, residence, education level, and occupation. The second part of the questionnaire included the type and site of the faced cancer, the duration of suffering, besides; the number and purpose of hospital visits. Treatment was also investigated.

This study was approved Sohag faculty of medicine and Sohag University Ethics
Committee. Furthermore, the following fundamental principles were taken into consideration as the ethical considerations: doing the required coordination with the administrators through an introducing letter, providing the required explanations of the study and its objectives for the studied patients, and obtaining oral informed consent from them, voluntary participation in the study, anonymous responses to the questionnaire items, and confidential data analysis.

\section{Results}

\section{1- Socio-demographic characteristics of studied patients}

The results showed that most studied patients were females $(60.5 \%)$, married $(85 \%)$, in forty to less than sixty age group, unable to work in $(80 \%)$ of the studied population and (90\%) inhabit Sohag governorate

\begin{tabular}{|c|c|c|c|c|c|c|c|c|}
\hline \multicolumn{2}{|c|}{ Table em } & \multicolumn{2}{|c|}{$\begin{array}{c}\text { Total } \\
\mathrm{N}=550\end{array}$} & \multicolumn{2}{|c|}{$\begin{array}{c}\text { SUH } \\
\mathrm{N}=215\end{array}$} & \multicolumn{2}{|c|}{$\begin{array}{c}\text { SCC } \\
\mathrm{N}=335\end{array}$} & \multirow[t]{2}{*}{$\begin{array}{c}\mathbf{X 2} \\
(\mathbf{p})\end{array}$} \\
\hline & & No. & $\%$ & No. & $\%$ & No. & $\%$ & \\
\hline \multirow[t]{2}{*}{ Gender } & Male & 217 & 39.5 & 99 & 46.1 & 118 & 35.2 & \multirow{2}{*}{$\begin{array}{l}6.421 \\
(0.011)\end{array}$} \\
\hline & Female & 333 & 60.5 & 116 & 53.9 & 217 & 64.8 & \\
\hline \multirow{3}{*}{$\begin{array}{l}\text { Age, } \\
\text { years }\end{array}$} & 20 - & 113 & 20.6 & 57 & 26.6 & 56 & 16.8 & \multirow{3}{*}{$\begin{array}{l}8.306 \\
(0.016)\end{array}$} \\
\hline & $40-$ & 257 & 46.7 & 89 & 41.4 & 168 & 50.1 & \\
\hline & $60+$ & 180 & 32.7 & 69 & 32.0 & 111 & 33.1 & \\
\hline \multirow{3}{*}{$\begin{array}{l}\text { Residence } \\
\text { in Sohag }\end{array}$} & Rural & 450 & 81.8 & 171 & 79.5 & 279 & 83.3 & \multirow{3}{*}{$\begin{array}{l}5.146 \\
(0.076)\end{array}$} \\
\hline & Urban & 45 & 8.2 & 15 & 7.0 & 30 & 8.9 & \\
\hline & Outside & 55 & 10.0 & 29 & $\mathbf{1 3 . 5}$ & 26 & 7.8 & \\
\hline \multirow{3}{*}{$\begin{array}{l}\text { Marital } \\
\text { status }\end{array}$} & Single & 60 & 10.9 & 24 & 11.2 & 36 & 10.7 & \multirow{3}{*}{$\begin{array}{l}3.174 \\
(0.366)\end{array}$} \\
\hline & Married & 473 & 86.0 & 183 & 85.1 & 290 & 86.6 & \\
\hline & Others & 17 & 3.1 & 8 & 3.7 & 9 & 2.7 & \\
\hline \multirow{2}{*}{$\begin{array}{l}\text { Education } \\
\text { al level }\end{array}$} & Illiterate & 435 & 79.1 & 162 & 75.3 & 273 & 81.5 & \multirow{2}{*}{$\begin{array}{l}6.173 \\
(0.103)\end{array}$} \\
\hline & Educated & 27 & 20.9 & 10 & 24.7 & 17 & 18.5 & \\
\hline \multirow{3}{*}{$\begin{array}{l}\text { Ability to } \\
\text { work }\end{array}$} & Unable & 460 & 83.6 & 176 & 81.9 & 284 & 84.7 & \multirow{3}{*}{$\begin{array}{l}9.244 \\
(0.236)\end{array}$} \\
\hline & Able & 90 & 16.4 & 39 & 18.1 & 51 & 15.3 & \\
\hline & Satisfactory & 47 & 8.5 & 16 & 7.4 & 31 & 9.3 & \\
\hline
\end{tabular}

Table (1): Sociodemographic characteristics of the studied oncology patients 
SOHAG MEDICAL JOURNAL

Vol. 24 No.1 Jan 2020
Pattern of cancer in Sohag Governorate

Tasneem Mohammed Bakheet

\section{2 - Distribution of cancer}

\section{patients by illness status}

\section{a- By the site of cancer}

The most tremendously occurring cancer was the breast cancer $(29.6 \%)$ followed by bladder (9.3\%), nonHodgkin lymphoma (9.1 \%), colorectal $(8.2 \%)$ and lung cancers $(6.7 \%)$, then came other types figure (1).

\section{b- Purpose, frequency of seeking} health service at oncology institutes and period of the illness

Table (2) demonstrates that most of the oncology patients about (60 \%) attended both institutes in order to receive treatment. And $25 \%$ of the cases came to follow up their illness conditions;

otherwise, more than one purpose or even making sophisticated investigations came after in either SUH or in SCC. There was high statistically significant difference between S.U.H \& S.C.C regarding the distribution of the studied sample by the purpose of seeking the hospital where $73 \%$ of total cases in university hospital \& $51.3 \%$ of total cases in S.C.C. came for receiving treatment; whereas $16.7 \%$ of cases in S.U.H and $7.5 \%$ of cases in S.C.C came for multiple purposes. Regarding follow up purpose there were $37.9 \%$ of cases in S.C.C in comparison with only $5.1 \%$ of cases in S.U.H. Only $5.1 \%$ of cases in S.U.H and $3.3 \%$ of cases in S.C.C came for performing investigations. Table (4) show that $(79.5 \%)$ seek the service repeatedly more than one time as shown in while table (4) shows the average period of stay in the hospital where 57\% of respondents stayed less than month in the hospital and $28.5 \%$ were chronic patients and stayed more than three months up to one year, a small percentage $2.2 \%$ stayed more than year. The interview visit was the first visit in 113 cases $(20.5 \%), 64$ in SUH and 49 in SCC;

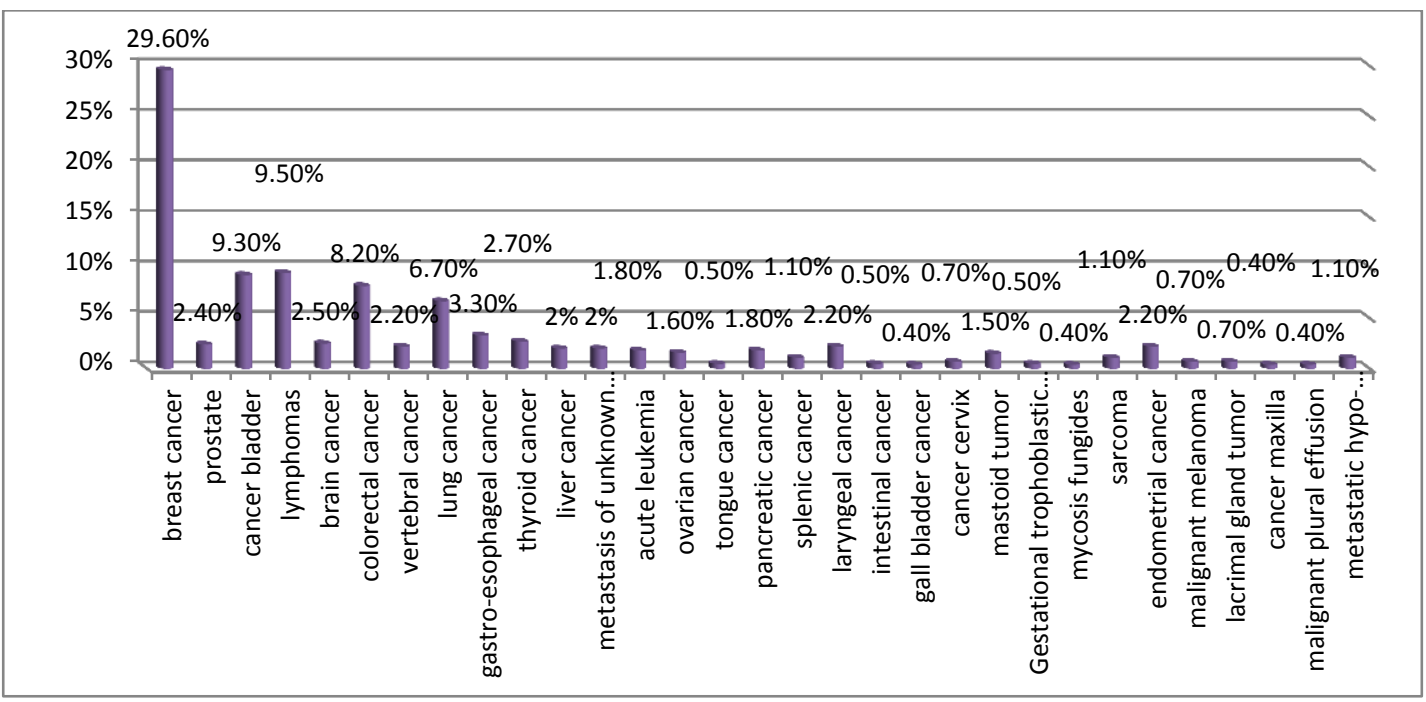

Fig (1): Distribution of cancer patients by type of cancer on final diagnosis in either institute, SUH and SCC 
SOHAG MEDICAL JOURNAL

Vol. 24 No.1 Jan 2020
Pattern of cancer in Sohag Governorate

Tasneem Mohammed Bakheet

\begin{tabular}{|c|c|c|c|c|c|c|c|}
\hline \multirow[t]{3}{*}{ Purpose } & \multicolumn{5}{|c|}{ Institute } & \multirow{2}{*}{\multicolumn{2}{|c|}{$\begin{array}{c}\text { Total } \\
\mathbf{N}=\mathbf{5 5 0}\end{array}$}} \\
\hline & \multicolumn{2}{|c|}{$\begin{array}{c}\text { Sohag University } \\
\text { Hospital } \\
\text { N }=215\end{array}$} & \multicolumn{2}{|c|}{$\begin{array}{c}\text { Sohag } \\
\text { Cancer } \\
\text { Center } \\
\mathbf{N}=335\end{array}$} & $\begin{array}{c}\text { p- } \\
\text { value }\end{array}$ & & \\
\hline & No. & $\%$ & No. & $\%$ & \multirow[t]{5}{*}{0.000} & No. & $\%$ \\
\hline $\begin{array}{l}\text { Receiving } \\
\text { treatment }\end{array}$ & 157 & 73 & 172 & 51.3 & & 329 & $\begin{array}{c}59 . \\
8\end{array}$ \\
\hline $\begin{array}{c}\text { For } \\
\text { investigation }\end{array}$ & 11 & 5.1 & 11 & 3.3 & & 22 & 4 \\
\hline For follow up & 11 & 5.1 & 127 & 37.9 & & 138 & $\begin{array}{c}25 . \\
1\end{array}$ \\
\hline $\begin{array}{c}\text { For multiple } \\
\text { purposes }\end{array}$ & 36 & 16.7 & 25 & 7.5 & & 61 & 11. \\
\hline
\end{tabular}

Table (2): Distribution of the studied sample by purpose of seeking the service

\begin{tabular}{|c|c|c|c|c|c|c|c|}
\hline \multirow[t]{3}{*}{ Times } & \multicolumn{5}{|c|}{ Institute } & \multirow{2}{*}{\multicolumn{2}{|c|}{$\begin{array}{c}\text { Total } \\
\mathrm{N}=550\end{array}$}} \\
\hline & \multicolumn{2}{|c|}{$\begin{array}{c}\text { S.U.H } \\
\mathrm{N}=215 \\
\end{array}$} & \multicolumn{2}{|c|}{$\begin{array}{c}\text { S.C.C } \\
\mathrm{N}=335 \\
\end{array}$} & $\begin{array}{c}\mathrm{p}- \\
\text { value }\end{array}$ & & \\
\hline & No. & $\%$ & No. & $\%$ & \multirow{5}{*}{$\begin{array}{c}0.00 \\
0\end{array}$} & No. & $\%$ \\
\hline $1-3^{*}$ & 120 & 55.8 & 164 & 49 & & 284 & 51.6 \\
\hline $4-6$ & 32 & 14.9 & 34 & 10.1 & & 66 & 12 \\
\hline $7-9$ & 19 & 8.8 & 107 & 31.9 & & 126 & 22.9 \\
\hline $10+$ & 44 & 20.5 & 30 & 9 & & 74 & 13.5 \\
\hline
\end{tabular}

\section{Table (3): Frequency of} attendance for the service

*First visit was detected in 113 cases $(20.5 \%), 64$ in SUH and 49 in SCC.

Table (4): Period of stay in the hospital

\begin{tabular}{|c|c|c|c|c|c|c|}
\hline \multirow{2}{*}{ Times } & \multicolumn{4}{|c|}{ Institute } & \multicolumn{2}{c|}{$\begin{array}{c}\text { Total } \\
\text { N=550 }\end{array}$} \\
\cline { 2 - 7 } & \multicolumn{2}{|c|}{$\begin{array}{c}\text { Sohag } \\
\text { University } \\
\text { Hospital } \\
\mathrm{N}=215\end{array}$} & \multicolumn{2}{c|}{$\begin{array}{c}\text { Sohag Cancer } \\
\text { Center } \\
\mathrm{N}=335\end{array}$} & \multicolumn{2}{c|}{} \\
\cline { 2 - 7 } & No. & $\%$ & No. & $\%$ & No. & $\%$ \\
\hline$<1$ month & 141 & 65.6 & 174 & $\begin{array}{c}51 . \\
9\end{array}$ & 315 & 57.3 \\
\hline $\begin{array}{c}1-3 \\
\text { months }\end{array}$ & 37 & 17.2 & 29 & 8.7 & 66 & 12 \\
\hline $\begin{array}{c}>3 \text { months } \\
-1 \text { year }\end{array}$ & 30 & 14 & 127 & $\begin{array}{c}37 . \\
9\end{array}$ & 157 & 28.5 \\
\hline$>1$ year & 7 & 3.3 & 5 & 1.5 & 12 & 2.2 \\
\hline
\end{tabular}

\section{Discussion}

In Birna Abdosh study ${ }^{2}$ in Ethiopia, 2015, of a total 518 patients; the majority were in the age group 15-30 (58.9\%),46.7\% of our respondents were $40-<60$ years age group; both studies found that most of the cancer patients were in productive ages but ours were older mostly because of delayed seeking medical advice until advanced stages of the illness. They came from out- side of the region (53\%) [while being $10 \%$ only in the present study] as most patients preferred the capital hospitals and the presence of cancer center in each governorate in most of the cases. In Romania study ${ }^{3}$, more than half $(52.57 \%)$ had ages between 25-34 (productive period also) and had university degrees (82.63\%), having technical jobs (30.09\%) and managerial jobs $(28.38 \%)$, on the contrary 
SOHAG MEDICAL JOURNAL

Vol. 24 No.1 Jan 2020
Pattern of cancer in Sohag Governorate

Tasneem Mohammed Bakheet
$79.1 \%$ were illiterate in the present study . Income levels varied from moderate (38.42\%) to high (21.81\%). The majority of this study patients were disabled and didn't work; (> $80 \%$ ) and had a very low income ( $>90 \%)$.

1. Characteristics related to the patient's health status and Use of health services

In Romania study by Victor ${ }^{3}$, patients went for a health consultation for routine check-ups (73.25\%) and for analysis $(18.25 \%)$ while in our study the purposes of seeking health care at the time of interviewing were $59 \%$ for receiving treatments and $25 \%$ for follow up $11 \%$ for multiple purpose and only $4 \%$ for investigations.

Ware et al ., $1990{ }^{4}$ noted that greater use of health services is associated with greater satisfaction. Less support for the hypothesis that more frequent visits to health care services are related to higher patient satisfaction scores is reported by Pascoe while the majority of the researches did not find any relationship at all. The most prevalent number of patient visits to the cancer institute in the current study at the interview time was from one to three time.

\section{2. cancer distribution by site}

In the current study The most tremendously occurring cancer was the breast cancer $(29.6 \%)$ followed by bladder $(9.3 \%)$, lymphoma (9.1\%), colorectal (8.2 $\%)$ and lung cancers $(6.7 \%)$, then came other types. While, cancer incidence rates at national and regional level of Egypt, based upon results of National Cancer Registry Program (NCRP) Commonest sites were liver $(23.8 \%)$, breast $(15.4 \%)$, and bladder (6.9\%) (both sexes): liver (33.6\%) and bladder (10.7\%) among men, and breast $(32.0 \%)$ and liver (13.5\%) among women. The pattern of cancer indicated the increased burden of liver cancer. Breast cancer occupied the second rank ${ }^{5}$

\section{Conclusion:}

Pattern of cancer indicated the increased burden of Breast cancer, comes after are lymphomas which occupy the second rank. Study of rates of individual sites of cancer might help in giving clues for preventive programs. Essential for planning cancer control actions, health care and allocation of resources. Here we project the cancer burden at the National level estimate

\section{References:}

1. Jeffrey,M.Albert Int $\mathrm{J}$ Radiat Oncol Biol Phys. 2013 Nov 1;87(3):432. doi: 10.1016/j.ijrobp.2013.06.2060.PMID: 24074912

2. Birna Abdosh (2015): The quality of hospital services in eastern Ethiopia: Patient's perspective. Ethiopian Journal of Health Development · October 2009. DOI: $\quad$ 10.4314/ejhd.v20i3.46854. uploaded by Birna Abdosh on 28 January 2015. pp198-200.

3. Victor Lorin Purcarea, Iuliana Raluca Gheorghe, Consuela Madalina Petrescu (2013): The Assessment of Perceived Service Quality of Public Health Care Services in Romania Using the SERVQUAL Scale. Procedia Economics and Finance 6 ( 2013 ) 573 585, available at: www.sciencedirect.com.

4. Ware JE, Berwick DM. Conclusions and Recommendations. Medical Care. 1990;28:S39-44. [PubMed] [Google Scholar]

5. Amal $S$ Ibrahim, Hussein $M$ Khaled, Nabiel Nh Mikhail, Hoda Baraka, Hossam Kamel J Cancer Epidemiol. 2014;2014:437971 doi: 10.1155/2014/437971. Epub 2014 Sep 21 